\title{
News and Sectoral Comovement
}

\section{Working Paper}

\section{Author(s):}

Lamla, Michael J.; Lein, Sarah M.; Sturm, Jan-Egbert (D)

Publication date:

2007-12

Permanent link:

https://doi.org/10.3929/ethz-a-005502910

Rights / license:

In Copyright - Non-Commercial Use Permitted

Originally published in:

KOF Working Papers 183 


\section{KOF Working Papers}

News and Sectoral Comovement

Michael J. Lamla, Sarah M. Lein and Jan-Egbert Sturm 


\section{KOF}

ETH Zurich

KOF Swiss Economic Institute WEH D 4

Weinbergstrasse 35

8092 Zurich

Switzerland

Phone +41446324239

Fax +4144 6321218

www.kof.ethz.ch

kof@kof.ethz.ch 


\title{
News and Sectoral Comovement*
}

\author{
Michael J. Lamla ${ }^{\dagger}$ Sarah M. Lein ${ }^{\ddagger}$ Jan-Egbert Sturm ${ }^{\S}$
}

December 2007

\begin{abstract}
This paper tests the existence of strategic information complementarities as a source of sectoral comovement. A theoretical model derived in Veldkamp and Wolfers (2007) explains sectoral comovement by the assumption that firms rely too much on aggregate information to make output decisions. We find empirical support for this hypothesis: news on aggregate developments, on average, affect firms production plans significantly more than news on sector-specific developments. This result is based on a rich dataset on firm survey and media releases for Germany comprising 01/1999-07/2006.
\end{abstract}

JEL classification: E32, D82.

Keywords: Media reporting, news, expectation driven business cycles, information complementarities, sectoral comovement.

${ }^{*}$ We thank Laura Veldkamp and the participants of the European Economic Association Meeting 2007, Budapest, Hungary and the German Economic Association Meeting 2007, Munich, Germany for helpful comments.

${ }^{\dagger}$ KOF Swiss Economic Institute, ETH Zurich, CH-8092 Zurich, Switzerland, E-mail: lamla@kof.ethz.ch

${ }^{\ddagger}$ KOF Swiss Economic Institute, ETH Zurich, CH-8092 Zurich, Switzerland, E-mail: lein@kof.ethz.ch

${ }^{\S}$ KOF Swiss Economic Institute, ETH Zurich, CH-8092 Zurich, Switzerland, E-mail: sturm@kof.ethz.ch 


\section{Introduction}

One of the stylized facts of business cycles is that output in most sectors increases and decreases together, a phenomenon known as industrial or sectoral comovement. Notably, this strong comovement cannot be found in sectoral productivity. ${ }^{1}$ The latter finding is inconsistent with the claim that sectoral comovement must be driven by relatively strong aggregate shocks (Lucas, 1977). This phenomenon of stronger output correlation across sectors, compared to productivity, has been labelled the excess comovement puzzle.

A recent theoretical model that is able to generate such an excess comovement is put forward by Veldkamp and Wolfers (2007). In their model, the source of the excess comovement are strategic information complementarities. They argue that important information is mostly available on a very aggregate basis. Thus, companies have to deduct from such general information the particular news that are relevant for them, i.e. the sector-specific component of information. As this is obviously just partly possible the correlation between the individual sectors is much higher than if full information would be available.

Overall, this idea seems plausible. In reality, it is easier to obtain information on economic activity of the whole economy as on individual sectors. For instance, several research institutes compete in providing forecasts about the economic outlook. Their results are then subject to an intensive coverage in the media. On the other hand, there is only little activity in detailed sectoral forecasts. This implies that obtaining reliable and timely sectoral forecasts is a much harder, and hence more costly, for firms.

The aim of this paper is to test the empirical relevance of the theoretical model presented by Veldkamp and Wolfers (2007) and test whether news can indeed affect firms' expectations and perceptions, and, more specifically, whether aggregate information is the dominating source of information.

For this purpose we employ data on production plans and business expectations of firms as gathered by the business tendency surveys of the German Ifo Institute as well as a new data set that captures economic news distributed by the German media. We collect news on

\footnotetext{
${ }^{1}$ See Hornstein (2000) and Veldkamp and Wolfers (2007).
} 
the stance on the economy and on individual sectors. The media data is kindly provided by Mediatenor, a media research institute. Our analysis employs a detailed data set comprising 01/1998-07/2006 using up to 618 available observations. Our data reveals that the aggregate economic situation receives substantial more attention in the media compared to news on individual sectors. For instance, the sector textiles appears ten times less often in the media than information on the German economy as a whole. ${ }^{2}$

Our results can be summarized as follows. First we test whether news can affect expectations of firms at all. Then we check how the news on the whole economy as well as on sector-specific developments impact expectations and perceptions of firms. We show that news affect firms' assessment of their economic outlook. In turn, these expectations have explanatory power for future and actual economic developments. These findings support recent research that stresses the role of news and expectations on business cycles (e.g. Beaudry and Portier, 2004 and Jaimovich and Rebelo, 2006).

In a second step we test the strategic information complementarities theory. We find that firms in different sectors react more to news on the whole economy as compared to news on their own sector. As information on the economy drives the future outlook of firms in a given sector more than news about their own specific sector, the mechanism described in Veldkamp and Wolfers (2007) that firms' inferences are based on common information, generating the observed excess comovement in sectoral output, compared to sectoral TFP, is supported by our findings. Hence, information complementarities can be an important explanation for sectoral comovement. Finally, we investigate the impact of news on each sector individually. We find quite strong heterogeneity across the different sectors. These might be explained by different degrees of reliance on information and proneness to shocks. We test the robustness of these findings by including actual economic and sector-specific production figures. We find that news still have a significant and economically meaningful impact on firms' expectations.

The remainder of this paper is organized as follows. Section 2 outlines theoretical contributions that link business cycles with news and information. Section 3 reveals that the excess

\footnotetext{
${ }^{2}$ For more details see also Figure 2.
} 
comovement is also present in German data. Section 4 discusses the data, while Section 5 presents our model and the estimation approach. Section 6 reports our empirical results. The final section concludes.

\section{The Role of Expectations, News and Information in Busi- ness Cycle Models}

In this section we first discuss whether, in theory, news can affect the economy and generate business cycles. Second, we review the role of incomplete and costly information as a driver of sectoral comovement.

The role of news as a driving force for expectations and their important role in business cycles have already been noted by Pigou (1927). However, real business cycle models that give a theoretical foundation in a neoclassical setting for expectation-driven business cycles have only quite recently been developed by Beaudry and Portier (2004). ${ }^{3}$ Jaimovich and Rebelo (2006) show that news about future TFP or investment-specific technical change can generate business cycles with volatility, comovement, and persistence of aggregates that are empirically plausible. ${ }^{4}$ The introduction of news in their model can generate recessions and expansions only by affecting expectations about future fundamentals. The existence of strong sectoral comovement in output, however, is not directly explained in these models.

Some of the earlier explanations claim that sectoral comovement must be driven by relatively strong aggregate shocks (Lucas, 1977), which are likely to be the primary source of business cycles. ${ }^{5}$ However, the explanation put forward by Lucas has been questioned in the more recent literature. For example, Hornstein (2000) shows that the observed comovement

\footnotetext{
${ }^{3}$ One of the main ingredients in the model is that intermediate good producers exhibit cost complementarities when supplying intermediate goods to different sectors of the economy.

${ }^{4}$ They introduce three elements in the model. First, variable capacity utilization increases output in response to news about the future. Second, adjustment costs to investment give incentives to react immediately to expected future technical progress. The third element is the assumption of preferences that allow for a timevarying wealth effect on labor supply, which implies a rise in hours worked in response to positive news about future TFP.

${ }^{5}$ Lucas argues that if the economy is subject to a large number of industry-specific disturbances which are unrelated to each other, one would expect that these disturbances change the relative productivity levels of inputs. This change in relative productivity levels should lead to a reallocation of inputs. Hence, input use should decline in sectors with falling relative productivity levels and should rise in sectors with rising relative productivity levels.
} 
in output cannot be explained by basic real business cycle models without having employment moving in the opposite direction in different sectors. However, this does not match reality. Instead a strong comovement across sectors also in terms of employment, investment and value-added exists and has been documented by Hornstein (2000), Christiano and Fitzgerald (1998) and Murphy et al. (1989).

Although this sectoral comovement is an important feature of business cycles, macroeconomic research has not yet found a fully sufficient explanation for it. For instance, Christiano and Fitzgerald (1998) stress that “...explanations for this comovement (...) [are] still not satisfactory". Also Hornstein (2000) notes that “...the problem clearly has not been addressed successfully" and recently this was re-emphasized by Rebelo (2005) who writes that "exploring the comovement properties of business cycle models is an important, but under-researched topic in macroeconomics".

Also the still puzzling fact that there is significantly less comovement of industry total factor productivity (TFP) than of industry output and labor input suggests that aggregate productivity shocks cannot satisfactorily explain comovement and business cycles in general (Hornstein, 2000).

Alternative explanations of business cycle comovement are given by assuming complementarities. Such strategic complementarities arise when the optimal action of one agent is an increasing function of the actions taken by others. These models provide a basis for generating a positive comovement in sectoral activity and employment as described in Cooper and Haltiwanger (1996). ${ }^{6}$ Veldkamp and Wolfers (2007) show that one can explain both the high comovement of output and the lower comovement of total factor productivity (TFP) when complementarities in information acquisition are present.

In an island model of production, appended with an information sector, information about driving forces of output is costly. Because information is non-rival, high fixed cost of production and a low marginal cost of replication make it more efficient for firms to share the

\footnotetext{
${ }^{6}$ See also the review in Christiano and Fitzgerald (1998). They also point out that such complementarities can drive expectations, lead to self-fulfilling prophecies and are consequently another source for business cycle movements. See also Cooper and Andrew (1988), Benhabib and Farmer (1996) and Schmitt-Grohe (1997), amongst others.
} 
cost of discovering common shocks than to invest in uncovering detailed sectoral information. Hence, firms rely on similar information which implies that their actions are more correlated compared to the non-costly, full information scenario. This mechanism amplifies the effects of common shocks, relative to sectoral shocks. Although the idea of strategic information complementarities is intuitively appealing, testing for the empirical relevance of this theory has been challenging, mainly because measuring available information is exceedingly difficult. ${ }^{7}$

\section{Excess Sectoral Comovement in Germany}

We use simple correlation analysis to check whether the stylized facts reported for the U.S. also are present in German data. For the U.S. it is observed that the comovement between sector output is, for many sectors, stronger than the correlation between sector productivity. This phenomenon is labelled as excess comovement.

The firm's output decision is based on the equality of marginal returns and marginal costs. If the firms observe their own productivity and optimize their output decision accordingly, they should adjust their output growth in line with their productivity growth. If productivity increases the optimal response is, everything else equal, to generate more output. Thus, the sector-specific output comovement should correspond to the sector-specific productivity comovement.

To investigate this issue for Germany we rely on data from the Groningen Growth and Development Centre -industry growth accounting database. ${ }^{8}$ It comprises the time span 1980-2003.

We visualize the issue in Figure 1. It depicts the correlation over time of both output growth for each sector with the economy's aggregate output growth (output comovement, Y-

\footnotetext{
${ }^{7}$ Veldkamp and Wolfers (2007) present three empirical phenomena that should underpin the predictions of their theoretical model. First, they provide evidence that financial markets equity prices (which should reflect all information firms have) comove more than corporate earnings. This, however, should not be the case if firms are well-informed. Second, they put forward that sectors with more productivity variation relative to the aggregate show less excess comovement. Third, they show that the fact that firm-level volatility increased and aggregate volatility decreased, which implies that firm comovement decreased, can be explained by a long-run downward trend in the costs of information acquisition.

${ }^{8}$ Source: Groningen Growth and Development Centre, Industry growth accounting database, accessed September 2006, http://www.ggdc.net/.
} 
axis) and the sectoral total factor productivity growth (TFP) with the economy's aggregate TFP growth (productivity comovement, X-axis). At the 45-degree line the sectors' output comovement corresponds with the sectors' productivity comovement. In case a sector has a higher output comovement than productivity comovement, i.e. it is located above the 45-degree line, this sector exhibits excess comovement.

Indeed, Figure 1 shows that also for Germany an excess comovement is present. Many of the sectors are located above the 45-degree line, which implies that output comovement is higher than productivity comovement. In the upcoming analysis we will concentrate on six sectors. These sectors are Chemistry (CY), Electrics (ES), Cars (CS), Machinery (MY), Food (FD) and Textiles (TS). Except for Food all sectors exhibit the pattern of excess comovement. One could argue that the informational need in the food sector might be less pronounced as volatility as well as productivity growth are comparatively small and therefore the gains from acquiring new information and forecasts are comparatively low.

\section{Data}

Our analysis requires two sources of data. On the one hand, we need data on expectations and perceptions to monitor the current and expected state of business. For this purpose we employ survey data as published by the Ifo Institute for Economic Research to measure the economic sentiment and business expectations. On the other hand we need data that capture the information that is disseminated at a certain point in time. In order to be able to capture this, we utilize information that is spread by news magazines, newspapers and TV broadcasts. This media data is kindly delivered by Mediatenor, a media research institute. All measures are available on the economy level as a whole as well as on a sector-specific level.

Each month, the Ifo Institute sends a survey to nearly 7,000 firms in the sectors industry, construction and (retail and wholesale) trade all over Germany (Nerb, 2004). In general, this so-called Ifo Business Survey intends to capture the firms' appraisals of the business situation

and their short-term planning and expectations. For instance, it asks firms to judge their 
Figure 1: Comovement of Output and Productivity

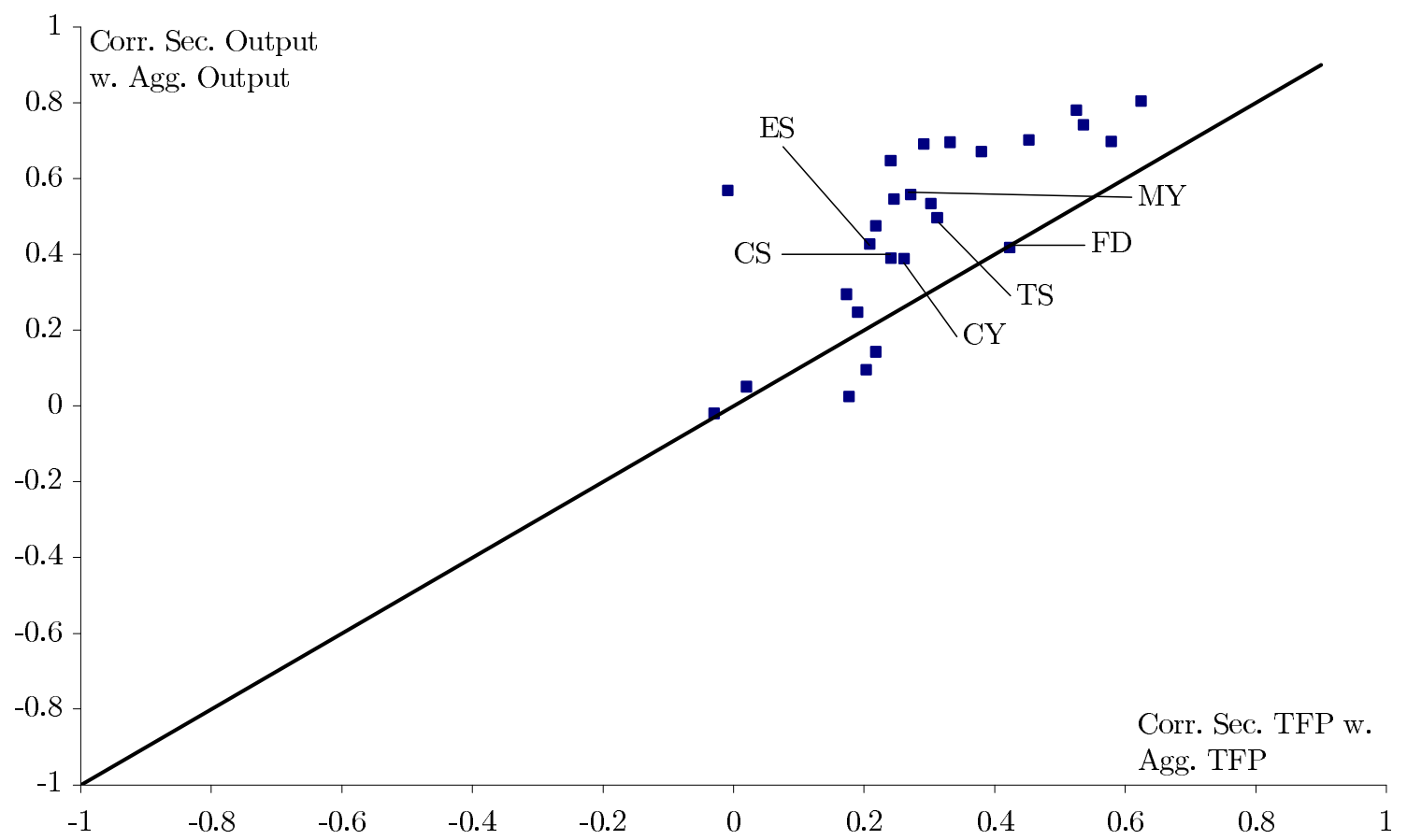

Solid line: 45-degree line. X-axis: correlation sector TFP growth and economy TFP growth, Y-axis: correlation sector output growth and economy output growth. Sector codes: Chemistry (CY), Electrics (ES), Cars (CS), Machinery (MY), Food (FD) and Textiles (TS). Source: Groningen Growth and Development Centre, Industry growth accounting database, accessed September 2006, http://www.ggdc.net/.

current business situation, tendencies in production volume against the previous month, and business expectations for the next six months. ${ }^{9}$

Firms are invited to answer most of the questions on a three-category scale: 'good/better', 'satisfactorily/same' or 'bad/worse'. The replies are weighted according to the importance of each firm and its industry, and aggregated. The percentage shares of the positive and negative responses to each question are balanced (ignoring the answer 'satisfactorily'). In this way each qualitative question is converted into a single Ifo indicator. ${ }^{10}$

\footnotetext{
${ }^{9}$ For more detailed information, we refer to Oppenländer (1997) or Sturm and Wollmerhäuser (2004). See Theil (1955) or Strigel (1990) for an earlier appraisal.

${ }^{10}$ The series of balances thus derived are linked to a base year (currently 1991) and seasonally adjusted.
} 
The well-known Ifo Business Climate Index combines the assessment of the current business situation and business expectations for the next six months. ${ }^{11}$ We will use the same two questions in this analysis to see whether news reports in the media affect the way in which firms assess the current business situation and whether these news reports change their expectations about future developments of the business climate of their own product line. ${ }^{12}$

In our analysis, we concentrate upon the manufacturing sector, which takes up by far the largest part of the Ifo Business Survey. ${ }^{13}$

The media data captures the number of articles and media releases on a daily frequency since 1999, including statements about the economy at an aggregate as well at a sector-specific level. According to its standards, Mediatenor captures news which are at least five lines long in case of printed media or last at least five seconds in the case of television reports. We rely on news reports stemming from 26 newspapers, weekly magazines and TV broadcasts. ${ }^{14}$

The classification used in the media data allows us to focus on the developments of the six sectors, i.e. Chemistry, Electrics, Cars, Machinery, Food and Textiles. The appearance of these sectors in the media relative to the amount of news on the economy as a whole is depicted in Figure 2. It shows that there is a clear difference between the intensity of media coverage on the whole economy compared to the amount of available sector-specific news. We see that there is substantially more catering of economy wide news relative to the coverage of sector specific developments. While the news on the automobile sector are

\footnotetext{
${ }^{11}$ To be precise, it is the geometric mean of the indicators derived from the balances to the question: 'We judge our current business situation for product group XY to be good, satisfactorily, or bad', and the question: 'With respect to the business cycle, our business situation for product group XY is expected to be somewhat better, more or less the same, or somewhat worse in the next six months.' Note that both questions refer to the 'business climate' and do not explicitly ask for developments in profits, or production. How the term 'business climate' should be interpreted is left open to the individual firms. Nevertheless, it is generally acknowledged that these qualitative results give a good indication of how actual industrial production evolves over the time.

${ }^{12}$ Hence, rather than focusing on the forecasting ability of Ifo Business Survey indicators, as is often done in literature (see, e.g. Fritsche and Stephan, 2002 and Hüfner and Schröder, 2002), this paper uses these indicators as direct measures for firms' sentiment and assessments of their own future development.

${ }^{13}$ We blend out the retail and wholesale part of the trade sector and the construction sector. The main reason is that we do not have data from Mediatenor on news reports covering these sectors.

${ }^{14}$ In detail following news sources are analyzed: Daily press: Frankfurter Allgemeine Zeitung, Welt, Süddeutsche Zeitung, Frankfurter Rundschau, Tageszeitung, Bild, Neue Züricher, Berliner, Volksstimmer, Sächsische, Westdeutsche Allgemeine Zeitung, Kölner Stadt-Anzeiger, Rheinischer Merkur; daily TVNews: ARD Tagesschau, Tagesthemen, ZDF Heute, Heute Journal, RTL Aktuell, SAT.1 18:30, ProSieben Nachrichten; Weekly Press: Spiegel, Focus, Die Woche, Wochenpost, Welt am Sonntag, Bild am Sonntag, Die Zeit.
} 
roughly one half as much, news on the food sector respectively news on textiles are about ten time less in the focus of the attention of the media. This implies that, even if we ignore for a moment the quality of the reports, it should be easier to obtain detailed information on the performance of the whole economy relative to information on the developments of individual sectors. Concerning our media data we want to stress also that the measure for economy wide news is not the average of sector-specific news but solely contains reports on assessment of the german economy as a whole. Our economy variable only captures news which address economy wide assessments. Moreover, the manufacturing industry accounts for roughly $25 \%$ of the german GDP and our six sector are only a part of it. Consequently there is no overlapping between our sector-specific and economy wide news measures.

Figure 2: Average number of reports per month on the economy in general vs. the individual sectors

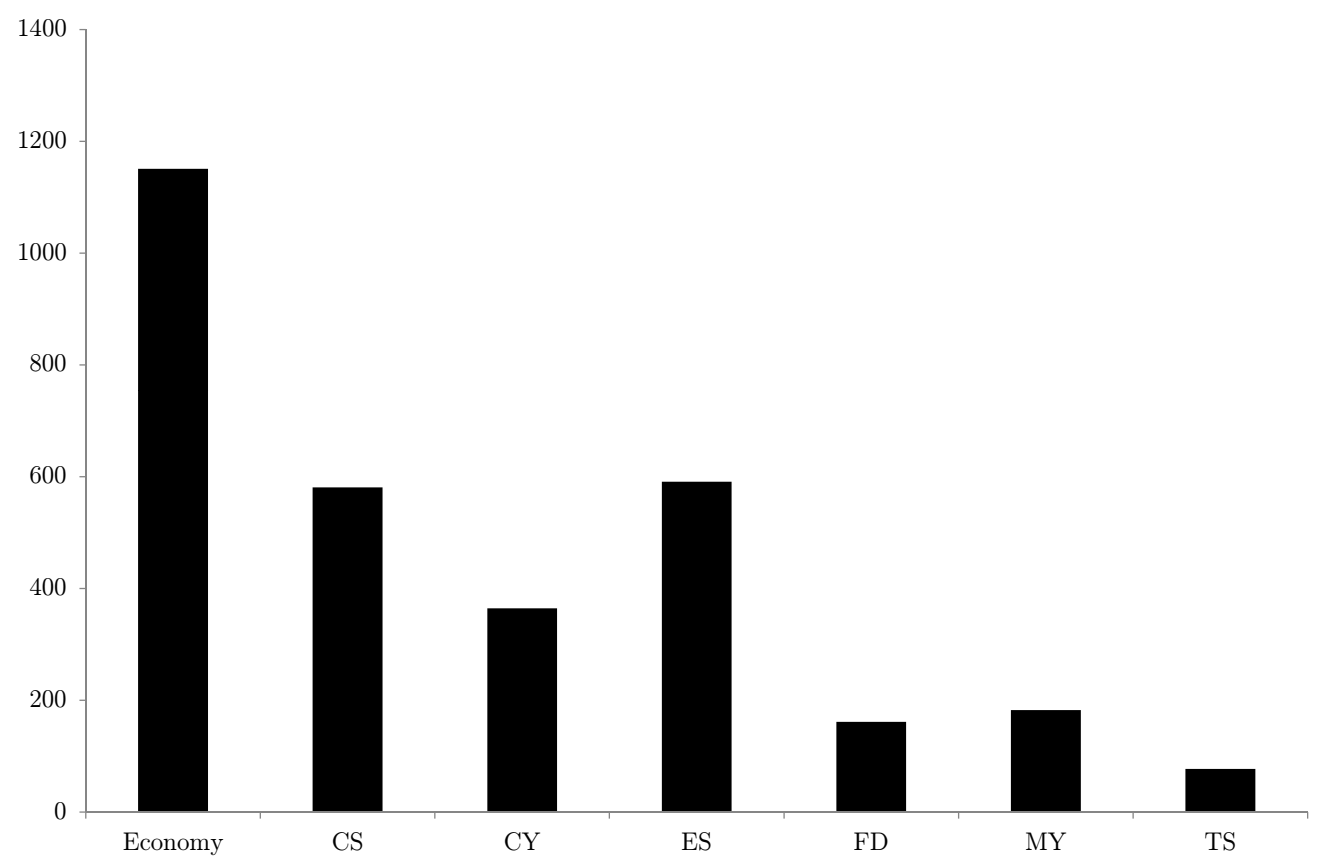

To allow comparison with the Ifo data, we focus on the balance between positive and negative news. Hence, we are left with various media indices capturing the transmitted 
Figure 3: Timeline of the Construction of the Media Indices and the Ifo Index

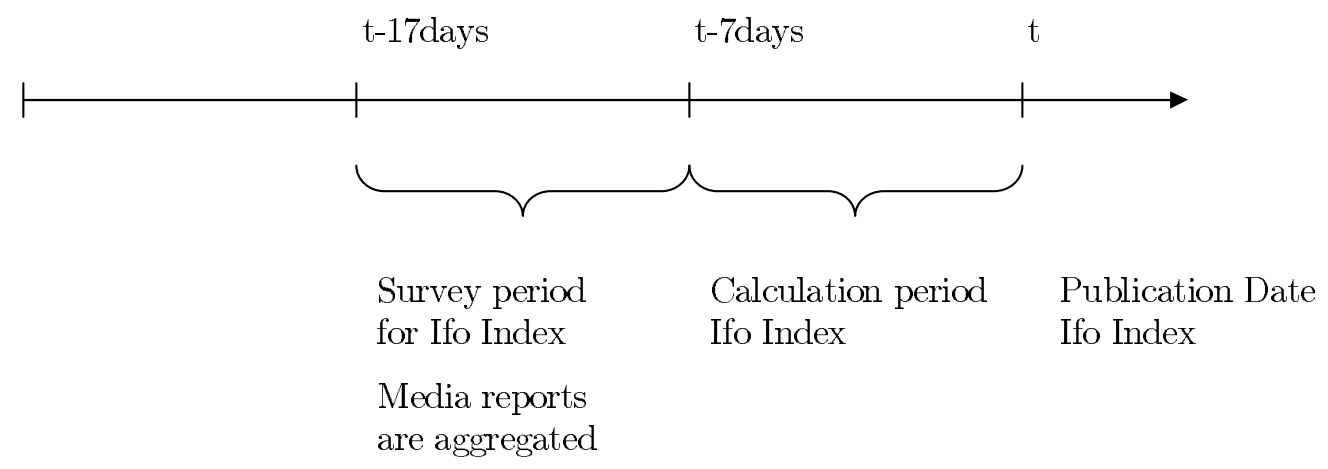

evaluations of current and future developments for the whole economy as well as for individual sectors.

Figure 3 visualizes the construction of the media index with respect to its aggregation in time. Usually the Ifo Business Climate Index is made public at the end of each month (i.e. between the 18th and the 24th of a month). Since it takes several days for the Ifo Institute to construct it, we assume the firms have already submitted the questionnaire a week before. For the same ten days during which firms fill out the Ifo Business Survey, we accumulate the media reports and construct our media indices. Hence, we assume that survey participants are especially affected to news transmitted during the period in which they fill out the forms. ${ }^{15}$ Because the Ifo Business Climate Index is made public one week later, by construction there cannot be any contemporaneous impact running from the publication of this indicator to our constructed news indicator. This fact also has direct implication for our estimation approach which will be explained in the following section. Thus, keep in mind that the media index refers to the same point in time as the Ifo index. However, as the Ifo index is unknown to the public, because it is published one week later, it is clear that the ifo index itself is not included in the contemporaneous media data.

\footnotetext{
${ }^{15}$ As a robustness check, we also construct media indices using data covering the full month. However, this does not alter the results qualitatively.
} 
Table 1: Summary Statistics - Individual Sectors and the Economy

\begin{tabular}{lrlccc}
\hline \multicolumn{1}{c}{ Variable } & Mean & Std. Dev. & Min. & Max. & Observations \\
\hline News Economy $\left(n^{a g}\right)$ & -23.7 & 18.1 & -64.2 & 21.0 & 103 \\
News Cars & 6.1 & 11.1 & -27.3 & 30.5 & 89 \\
News Chemistry & 6.9 & 12.2 & -28.1 & 34.8 & 89 \\
News Electronics & 5.6 & 11.4 & -23.5 & 33.6 & 89 \\
News Food & -1.0 & 15.4 & -53.3 & 27.0 & 89 \\
News Machinery & 4.9 & 14.8 & -55.1 & 33.3 & 89 \\
News Textiles & 15.3 & 17.8 & -20.0 & 66.7 & 89 \\
& & & & & \\
Ifo Situation Cars & 16.3 & 15.0 & -10.0 & 47.0 & 103 \\
Ifo Expectations Cars & 7.0 & 19.6 & -35.0 & 58.0 & 103 \\
Ifo Situation Chemistry & 9.9 & 15.1 & -18.0 & 47.0 & 103 \\
Ifo Expectations Chemistry & 10.4 & 13.7 & -26.0 & 35.0 & 103 \\
Ifo Situation Electronics & -3.4 & 18.8 & -35.0 & 32.0 & 103 \\
Ifo Expectations Electronics & 6.4 & 15.5 & -35.0 & 38.0 & 103 \\
Ifo Situation Food & -9.2 & 7.2 & -29.0 & 9.0 & 103 \\
Ifo Expectations Food & -2.6 & 8.0 & -29.0 & 17.0 & 103 \\
Ifo Situation Machinery & 1.7 & 17.3 & -30.0 & 45.0 & 103 \\
Ifo Expectations Machinery & 4.1 & 13.7 & -33.0 & 27.0 & 103 \\
Ifo Situation Textiles & -23.0 & 14.7 & -48.0 & 6.0 & 103 \\
Ifo Expectations Textiles & -6.3 & 12.3 & -40.0 & 16.0 & 103 \\
\hline
\end{tabular}

Table 2: Summary Statistics - Panel

\begin{tabular}{lrlccc}
\hline \hline \multicolumn{1}{c}{ Variable } & Mean & Std. Dev. & Min. & Max. & Observations \\
\hline News Economy $\left(n^{a g}\right)$ & -23.7 & 18.1 & -64.2 & 21.0 & 618 \\
News Sector $\left(n_{t}^{\text {sec }}\right)$ & 6.3 & 14.7 & -55.1 & 66.7 & 534 \\
Ifo Situation $\left(i^{s}\right)$ & -1.3 & 19.8 & -48.0 & 47.0 & 618 \\
Ifo Expectations $\left(i^{e}\right)$ & 3.2 & 15.3 & -40.0 & 58.0 & 618 \\
\hline
\end{tabular}


In Tables 1 and 2, we present the summary statistics. Table 1 offers the individual time series characteristics, while Table 2 refers to the stacked series used in the panel VAR analysis. The statistics are pooled results over all six sectors in our data. By construction, each variable can fluctuate between -100 and 100, where positive values indicate on balance more positive than negative assessments and vice versa. ${ }^{16}$ When facing the data it becomes evident that the media reporting on the economy as a whole is, with an average value of -23.7 , biased downward. Hence, these media reports have on average a rather pessimistic undertone. In contrast, media reports on sector-specific developments do not reveal such a pattern and seem more neutral in that respect. Looking at both the extreme values and the standard deviations, it becomes clear that all series face similar degrees of volatility. Figure 4 visualizes the movement of the Ifo Situation index in comparison to our aggregate news measure and the average sector-specific news measure. All three series are clearly correlated. The aggregate media index seems to be slightly more volatile compared to the sector-average news index. Moreover, both indices show a low degree of persistence in comparison to the Ifo Situation index. This is as expected. First, while the Ifo index is filtered, our series are raw and not adjusted. Second, the world is not changing that rapidly from one month to another and thus the overall sentiment should be less volatile as the media index. Not all stories which are made public and are incorporated in our news index are relevant and should affect the decision making process alike. Thus, some news stories are likely to affect agents' actions more than others.

\section{Model and Estimation Approach}

To derive our empirical setup, we first sketch a simple model explaining as of how firms form their expectations. ${ }^{17}$ Let $\Omega^{i}$ represent the information set for firm $i$. This information set is

\footnotetext{
${ }^{16}$ Although our variables are bounded there is little merit in applying the log-odds transformation, as the mass of observations is concentrated and more than two standard deviations away from the bounds.

${ }^{17}$ A more sophisticated model is provided by Veldkamp and Wolfers (2007).
} 
Figure 4: Media Indices and the Ifo Situation Indicator

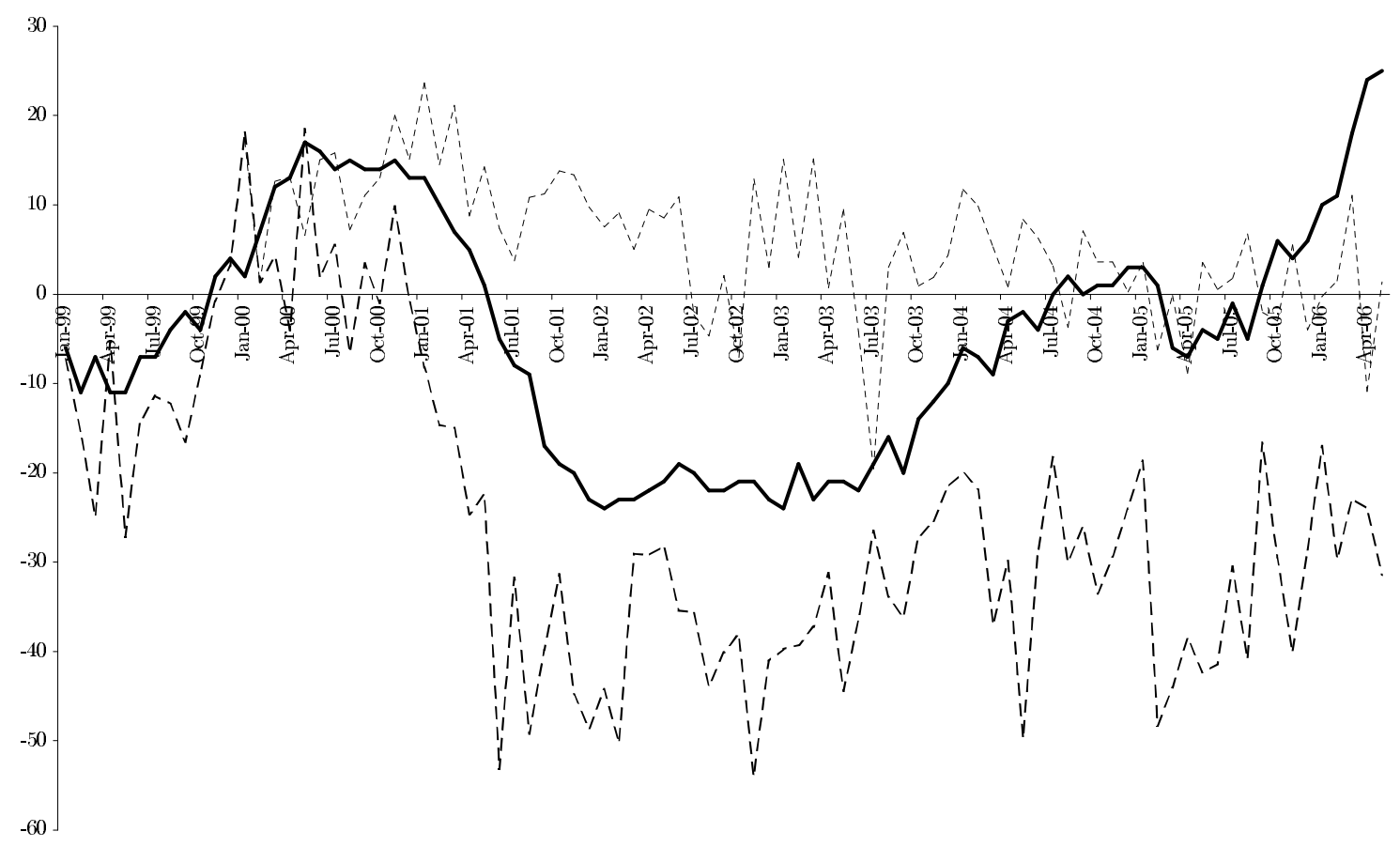

Solid line: Ifo Situation indicator; dashed thick line: media indicator whole economy; dashed thin line: media indicator sector average.

decomposed into two subsets of information: information from the aggregate economy $(a g)$ as well as sector-specific information $(\mathrm{sec})$ :

$$
\Omega^{i}=\Omega_{a g}^{i} \cup \Omega_{s e c}^{i}
$$

The information firm $i$ has on the aggregate economy and on its own sector is a subset of the entire information available for, respectively the aggregate economy $\Omega_{a g}$ and the sector $\Omega_{s e c}$ :

$$
\begin{aligned}
& \Omega_{a g}^{i} \subset \Omega_{a g}, \\
& \Omega_{s e c}^{i} \subset \Omega_{s e c} .
\end{aligned}
$$


As described in the introduction, the main feature of the model of strategic information complementarities is that sector-specific information is very costly to obtain. Information on the aggregate economy, however, is available for free or at very low costs. One example would be publicly or privately founded research institutes who do research on the economy and make their results freely available. Those results are usually edited by media companies and made public. Therefore, a firm is likely to inform itself on aggregate developments via the media. The information it observes on its own sector is to a much smaller extent available as it is much harder to obtain. First it is a greater effort to conduct research on a specific sector (data availability, etc.) and second there is much less demand for this information, which implies that there are lower incentives or much higher costs for institutes to generate this information. ${ }^{18}$ Especially, if we consider that information is non-rival in consumption and has marginal cost of replication, then the sector-specific information set is unlikely to be fully revealed. We label this observable part $\Omega_{o}$ :

$$
\Omega_{\text {sec }}=\Omega_{o} \cup \Omega_{u}
$$

The unobservable part, $\Omega_{u}$, has to be derived from other sources. As the economy-wide outlook also contains information for each sector $\left(\Omega_{a g} \cap \Omega_{u}\right)$, a firm might, for instance, use the media information on aggregate developments available to "guestimate" the sector-specific unobservable part. In that case, this implies

$$
\Omega_{\text {sec }}^{i}=\Omega_{o}^{i} \cup \Omega_{a g}^{i}
$$

Thus, a firm $i$ forms its future output decision based on its own information set about sector-specific and aggregate productivity shocks:

$$
\begin{aligned}
E_{t}\left(y_{t+1}^{i}\right) & =\alpha E_{t}\left(y_{t+1}^{i} \mid \Omega_{a g}^{i}\right)+\beta E_{t}\left(y_{t+1}^{i} \mid \Omega_{s e c}^{i}\right) \\
\Leftrightarrow E_{t}\left(y_{t+1}^{i}\right) & =\tilde{\alpha} E_{t}\left(y_{t+1}^{i} \mid \Omega_{a g}^{i}\right)+\tilde{\beta} E_{t}\left(y_{t+1}^{i} \mid \Omega_{o}^{i}\right) .
\end{aligned}
$$

\footnotetext{
${ }^{18}$ These costs become even more severe, if we think of generating this information on a high frequency, e.g. on a monthly basis.
} 
To sum up, both sector-specific as well as aggregate information are important for making output decisions at the firm level. Although it might be argued that the 'true' sector-specific information is more important for a firm's production plan, this information is costly to obtain and the observable part might be incomplete, imprecise or simply too costly to be ordered every month. ${ }^{19}$ To the contrary economy-wide information is provided (almost) freely as several research institutes provide accurate and reliable forecasts on future output and inflation. Their forecasts are subject to an intensive debate and thus catered by various media agencies. This implies that a firm's production decision will in practice rest largely upon aggregate information provided by the media. The more important this information channel is, the larger the effect of economy-wide media information will be on production plans of firms. ${ }^{20}$

We employ a type of the so-called Granger causality analysis to investigate the importance of media information on the assessment of current and expected business. In that way, we provide evidence with respect to the strategic complementarities hypothesis. To make our main hypothesis testable, we restate it to the following: The balance between positive and negative news is said to 'Granger cause' the assessment of the business climate and/or business expectations, if the time-series prediction of the Ifo indicators from their own past can be improved by adding lags of news balances to the equation. This interpretation of causality is, of course, intuitively attractive. It has therefore become widely accepted, although some of its implications are still under debate. ${ }^{21}$

Simple Granger-causality analysis may be obstructed by simultaneity effects: news may Granger cause business expectations, while at the same time the business situation causes news. To avoid this problem, we analyze Granger causality in a so-called 'Vector AutoRegression' (VAR) model. VAR methodology resembles simultaneous-equation modelling in that several endogenous variables are considered together. In a VAR, only endogenous variables enter: each variable is explained only by its own lagged values and the lagged values of

\footnotetext{
${ }^{19}$ One could argue that sector-specific news are provided via informal channels, like discussions with other companies, etc. The drawback of this channel is, however, the reliability of this information and to which extent it may be readily and timely available.

${ }^{20}$ See also Veldkamp and Wolfers (2007) for a formal model.

${ }^{21}$ For an early overview of pros and cons of Granger causality, see Granger (1980).
} 
the other endogenous variables. If necessary, deterministic variables, such as a constant or a trend, are included. As no conditions concerning the causal relationship of the variables need to be identified a priori, the simultaneity problem thus becomes solved. Since we are also interested in the direction of causality, this is a clear advantage.

Using our four variables of interest-Mediatenor news balances concerning sector news $\left(n_{t}^{s e c}\right)$ and news addressing the stance of the whole economy $\left(n_{t}^{a g}\right)$, the Ifo Business Expectation indicator $\left(i_{t}^{e}\right)$ and the Ifo Business Situation indicator $\left(i_{t}^{s}\right)$ - gives the following $\operatorname{VAR}(p)$ model:

$$
\left(\begin{array}{c}
n_{t}^{a g} \\
n_{t}^{s e c} \\
i_{t}^{e} \\
i_{t}^{s}
\end{array}\right)=\left[\begin{array}{c}
a_{10} \\
a_{20} \\
a_{30} \\
a_{40}
\end{array}\right]+\left[\begin{array}{llll}
A_{11}(L) & A_{12}(L) & A_{13}(L) & A_{14}(L) \\
A_{21}(L) & A_{22}(L) & A_{23}(L) & A_{24}(L) \\
A_{31}(L) & A_{32}(L) & A_{33}(L) & A_{34}(L) \\
A_{41}(L) & A_{42}(L) & A_{43}(L) & A_{44}(L)
\end{array}\right]\left(\begin{array}{c}
n_{t-1}^{a g} \\
n_{t-1}^{s e c} \\
i_{t-1}^{e} \\
i_{t-1}^{s}
\end{array}\right)+\left(\begin{array}{c}
e_{1 t} \\
e_{2 t} \\
e_{3 t} \\
e_{4 t}
\end{array}\right),
$$

where, for $j, k=1, \ldots, 4, a_{j 0}$ are the constants, $A_{j k}$ are polynomials of order $p$ in the lag operator $L$, and $e_{j t}$ are independent and identically distributed disturbance terms such that the covariance matrix $\Sigma=E\left(e_{j t} e_{k t}\right)$ is not necessarily zero for $j \neq k$.

Each equation in the system can be estimated by Ordinary Least Squares (OLS). Moreover, OLS estimates are consistent and asymptotically efficient if each has the same lag structure. Even though the errors are correlated across equations, system estimators do not add to the efficiency of the estimation procedure since the regressions have identical right-hand-side variables (Denton, 1978).

If the lagged values of the explanatory variable exert a statistically significant effect, then we have identified a Granger-causal impact (of a so-called strong form) (Kawai, 1980).

The Granger-causality testing procedure does not generally give us an estimate of the sign of the overall effect. In order to test whether there exists a positive or negative effect of one variable on another, we apply the neutrality test, in which we calculate the sum of the lagged values of an explanatory variable and test whether it significantly differs from zero (Zarnowitz, 1992, pp. 365-379). Hence, in this setting the analysis of a Granger-causal relation from news balances on the assessment of the (future) business climate boils down to testing whether 
each of the coefficients of the lag polynomials $A_{j k}(L)=A_{j k}^{1}, \ldots, A_{j k}^{p}$, specifically $A_{31}$ and $A_{41},\left(A_{32}\right.$ and $\left.A_{42}\right)$ in equation (8) differ from zero. If furthermore the sum of these elements is significantly different from zero, we know that news does have a long-run impact on the Ifo Business indicators. We estimate both the constrained and unconstrained systems as a whole and apply likelihood ratio tests.

As links between the equations hamper interpretation of individual coefficients, Sims (1980) proposes to analyze a VAR model by observing the reactions of the estimated system to different shocks over time. Just as an autoregression has a moving average representation, a VAR can be converted into a Vector Moving Average (VMA). The VMA representation allows us to trace the time path of various shocks on the variables in the VAR system.

Because the error terms are contemporaneously correlated, shocks that hit the economy affect all variables in the current period. Consequently, it is not possible to single out the effect of a separate shock. A standard solution for this identification problem is to impose restrictions of some kind. We use the Choleski factorization, which implies an ordering of the variables from the most pervasive, i.e. a shock to this variable affects all the other variables in the current period, to the least pervasive, i.e. a shock does not affect any other variable in the current period. In this manner, some economic structure is imposed on the computation of the impulse-response functions. Unfortunately, there are many ways to order the variables (for $k$ variables there are $k$ ! orderings), and, as noted for example by Cooley and LeRoy (1985) and Duggal et al. (1995), the choice of one particular ordering might not be innocuous. Of course, the importance of the ordering depends on the magnitude of the correlation coefficient between the error terms. If the estimated correlations are almost zero, the ordering is immaterial. We have used different orderings, which, however, did not change our conclusions. ${ }^{22}$ To give an indication of statistical reliability, we report the impulse responses along with a 95 per cent confidence interval, using a computational procedure developed by Giannini (1992), which is based on asymptotic Gaussian approximations of the distribution of the responses.

\footnotetext{
${ }^{22}$ Note, we also include contemporary values of our media variables in the VAR as they, by construction, cannot be influenced by the publication of the Ifo indices.
} 
Given that only data from 1999 onwards are available for this analysis, we use the above set-up in a panel data framework in which the constants in Equation (8) are replaced by sector dummies. We will focus on the manufacturing sector and using data for six different manufacturing branches. For further inference we will also investigate the responses to news on each sector individually.

\section{Empirical results}

Table 3 reports the statistics of the Granger causality and Neutrality tests. We opt for the Likelihood-Ratio test. However, the conducted Wald-tests lead qualitatively to identical results. We observe that there is a clear evidence that Ifo Expectations cause changes in the Ifo Situation index and not vice versa. This is as expected and reveals that the answers collected by the Ifo institute are genuine. Furthermore, we can see that news on the economy have a significant impact on Ifo Situation as well as on Ifo Expectation while sector-specific news do not affect both indicators substantially. These results correspond with the model predictions. Media directly effects the current perception of the economy but also is used to digest information for future business. Furthermore, firms use aggregate information to infer the future path of the economy. In addition, as the neutrality test is rejected, it seems there is a rather short-run effect of economy-wide news on expectations. While this analysis provides us with information concerning the significance and the direction of an impact of one variable on another, it gives no answer with respect to the time path of the impulse. Therefore, we additionally calculate the impulse response functions.

Figure 5 shows the impulse response functions. First and in line with the statistics reported in Table 3, Ifo Expectations have a significant impact on the actual business situation. The maximum impact is reached after about six months, the time horizon over which firms are asked to assess future developments. Which in turn implies that firms, on average, give coherent answers, being able to accurately describe their economic standing six months in advance. 


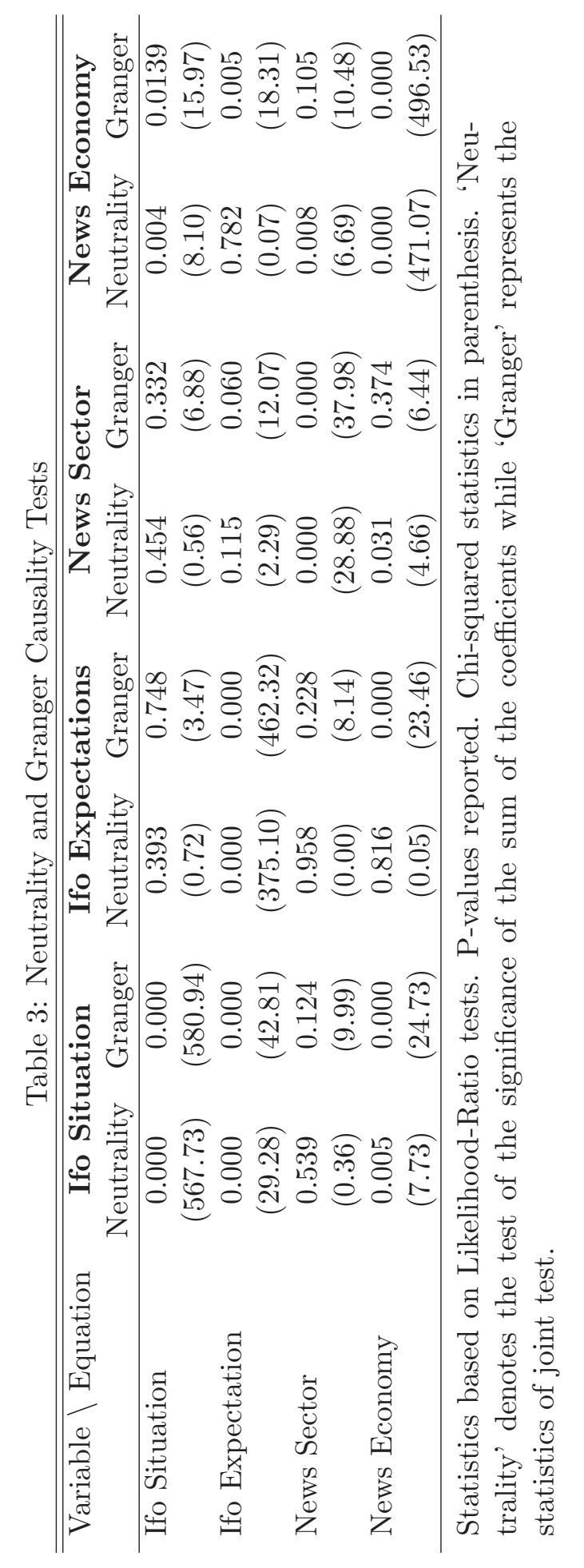


Moreover, we can confirm that media indeed shapes the opinion and assessment of the current and future business situation; media affects both Ifo Expectations as well as Ifo Situation. This again confirms results of the significance test. Moreover, we can add to this that news dealing with the economy as a whole exhibit a stronger impact on the Ifo index than sector-specific news. This affirms the importance of information complementarities. Due to information cost, companies rely on aggregate data in order to infer sector-specific information.

It is generally found that the Ifo index captures real movements in the economy quite well (see Nierhaus and Sturm, 2007). This suggests that information transmission via the media has indeed an impact on the real economy and thereby drives business cycles and amplifies sector comovement. Another evidence that supports the view that news are highly relevant for economic outcomes is provided by Mora and Schulstad (2007), who find that the information agents have about current GNP, i.e. first releases, matter more for their actions than the true ex-post figures of GNP. ${ }^{23}$

In view of the heterogeneous character of the manufacturing sector, we estimate each sector individually. Figure 6 depicts the impulse responses to a shock of news on the whole economy and of sector-specific news. For the sake of brevity, we just report these impulse responses and not the full set of impulse responses for each sector. ${ }^{24}$

While on average there is compelling evidence in favor of our proposition that aggregate information has a strong impact, there is some degree of heterogeneity in the response to a news shock across the sectors. For instance, the food sector is neither influenced by news on the economy as a whole nor by news on its own sector. On the other hand, sectors like textiles, chemistry, cars and machinery exhibit a clear pattern that matches our ex-ante considerations and the general picture. Finally, sector-specific news have a very pronounced impact on the Ifo Situation index for electronics.

\footnotetext{
${ }^{23}$ The authors study the degree to which expectations affect the evolution of the economy. They find that once GNP first releases are taken into account, the true (revised) value of GNP growth at time $t$ has no predictive power in explaining future growth rates at any time. Thus, all the predictive power lies in the unexpected part of the announcements, and not in the true level of growth.

${ }^{24}$ That is, we concentrate on the $A_{31}, A_{41}, A_{32}$ and $A_{42}$ polynomials in equation (8). The full set of results is available on request.
} 
The different impact between these sectors may be explained by different needs for sectorspecific information. This finding is consistent with the Veldkamp-Wolfers model. Firms make rational choices if they buy sector-specific information for a relatively high price or obtain only information on aggregate data for a relatively low price. If a firm in a given sector knows that the sectoral productivity developments are relatively close to the aggregate productivity developments, the loss of making decisions based on aggregate information only is lower than for firms that are in sectors where productivity developments are less synchronized. Hence, the loss of making decisions based on aggregate information is higher, the higher the difference between aggregate and sector-specific productivity developments. Another relevant aspect is the volatility of productivity growth. If it is high, there are higher costs associated with a mismatch between the actual output decision and the optimal output decision.

Thus, if this loss outweighs the costs firms have to pay for sector-specific information, they rationally choose to pay for obtaining this relatively costly information. This is also present in our results: for instance, the necessity of the food industry to base their decision on upcoming information is lower as food consumption patterns are quite stable over time and more importantly, the productivity growth of this sector is very low. ${ }^{25}$ Hence, the incentives to react to incoming news concerning the performance of the economy is much lower than in other sectors. ${ }^{26}$ Furthermore, we find support that sectors underlying rapid productivity growth and low correlation with the whole economy have more incentives to gather sectorspecific information, because a deviation would be extremely costly. When facing the outcome of electronics, with an average TFP growth of six percent, we observe that a shock to sectorspecific information has a more pronounced impact than an impact of economic news. In addition, this sector has the lowest correlation of sector productivity with economy-wide productivity. ${ }^{27}$ The remaining sectors react more to economy-wide news.

Finally, we present a robustness check for our results. One could argue that we only capture actual shocks which are consequently reported in the media. Thus, we attempt to

\footnotetext{
${ }^{25}$ TFP growth in the food sector is basically zero. Contrary, TFP growth of electronics is on average six percent. The average unweighted TFP growth over all sectors is about one percent.

${ }^{26}$ This is underlined by the low degree of volatility in this sector relative to the other sectors in our sample.

${ }^{27}$ Notably, the correlation of sector-specific productivity growth with economic-wide productivity growth is quite similar over all sectors considered in our study.
} 
extract the effect of current real economic events reported in the media. In order to control for that, we need to instrument our media indices with hard data on industrial production. That is, in a first stage our media data are regressed on both aggregate and sector-specific (ex post) industrial production growth in the same and the previous three months. We now interpret the residuals as news movements which are not backed up by actual real developments. Within the VAR framework, we now replace the original news variables by these newly constructed variables, 'News Economy' and 'News Sector'. As Figure 7 reveals hardly any changes emerge. Hence, information as distributed by the media appear to affect the firms' assessments of current and future developments.

\section{Conclusions}

Why are sector-specific developments highly correlated among each other? How come that sectoral comovement for output is stronger than for productivity? These are questions which we address in this paper. Both issues will be answered by considering how much of these dynamics can be attributed to information complementarities.

Recent theoretical work by Veldkamp and Wolfers (2007) highlights the role of news as an ingredient in business cycle movements. They suggest that high costs for sector-specific information force industries to rely to a large extent on economy-wide information which is more readily available. From this information they infer the necessary information for their own sector. As this implies that firm specific actions are based on similar information, this can explain why the sectoral comovement is more pronounced in output as compared to productivity. As we show in the paper this aspect of business cycles also holds for Germany.

Using German survey data from the Ifo institute as well as data on German media reporting, we find that media can indeed affect firms' perceptions and expectations. Moreover and more importantly, we find that economy-wide media information has a stronger impact on sector-specific business assessments than sector-specific media information has. This enforces theoretical models highlighting the role of news as an ingredient in business cycle movements. More specifically, our findings support the view of strategic interactions, driven by information 
acquisition aspects, as one source of business cycle comovement. Thus, strategic information complementarities, as addressed by Veldkamp and Wolfers (2007), can give an answer to the above questions.

Finally, we observe that there is a significant heterogeneity across sectors. The marginal utility of information may vary between industries. For some industries it is more crucial to have up-to-date and sector-specific information than for others. For instance, industries relying on large and possibly irreversible investments, facing greater volatility or stronger competition might be willing to invest more in sector-specific information. 


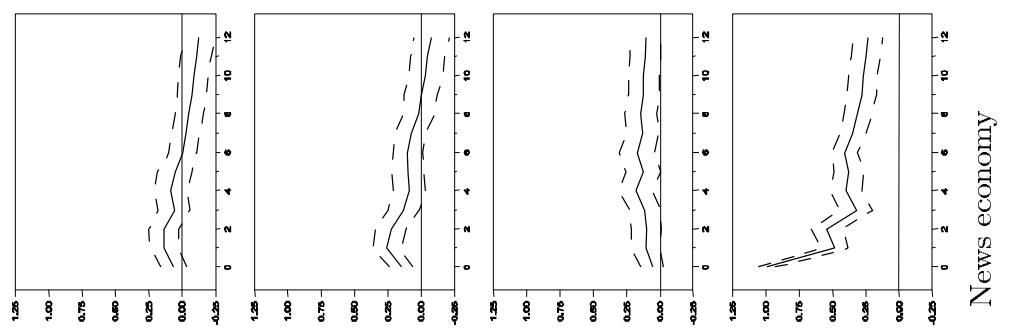

2
0
0
0
0
00
0
0
0
0
01
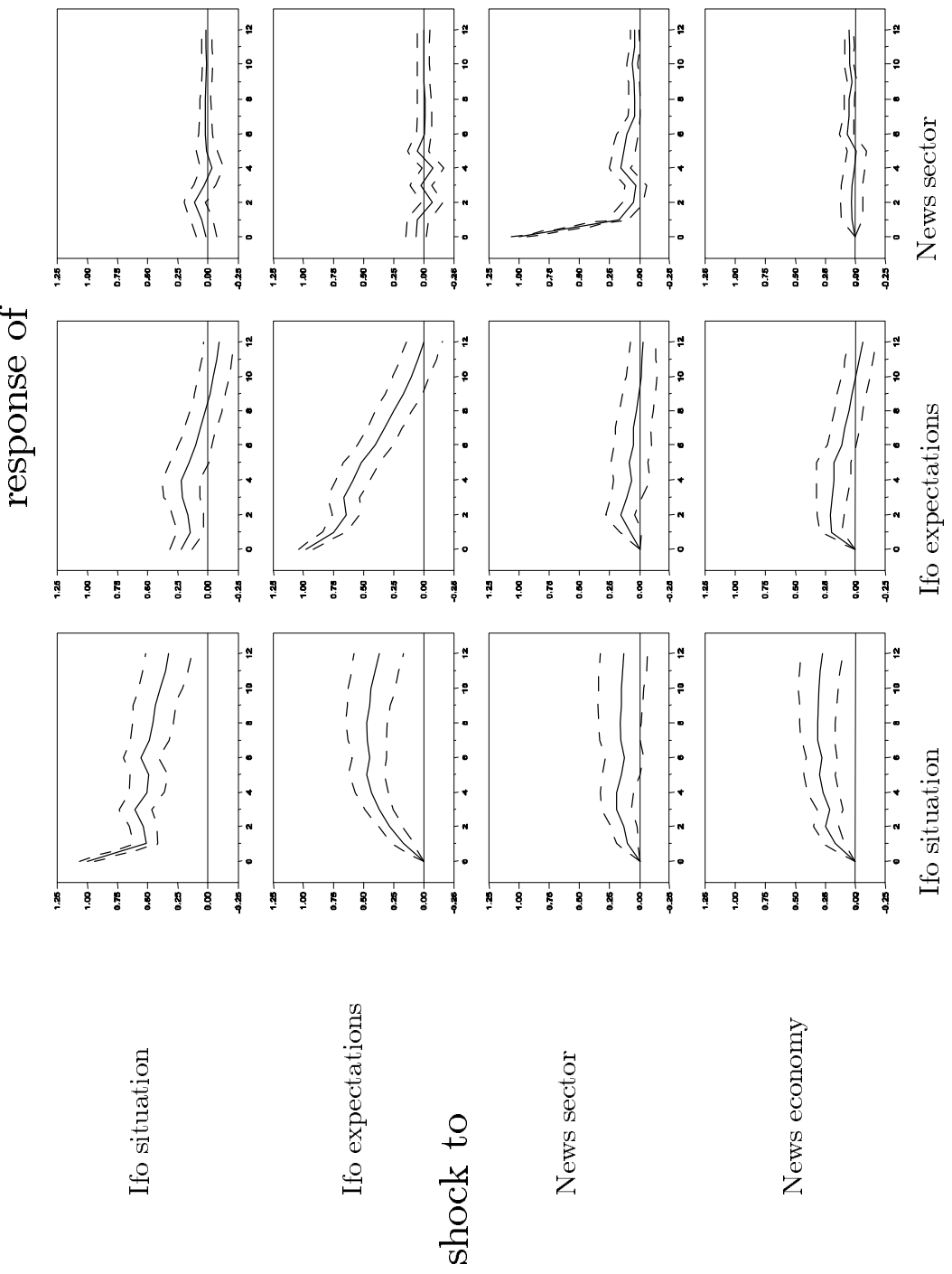

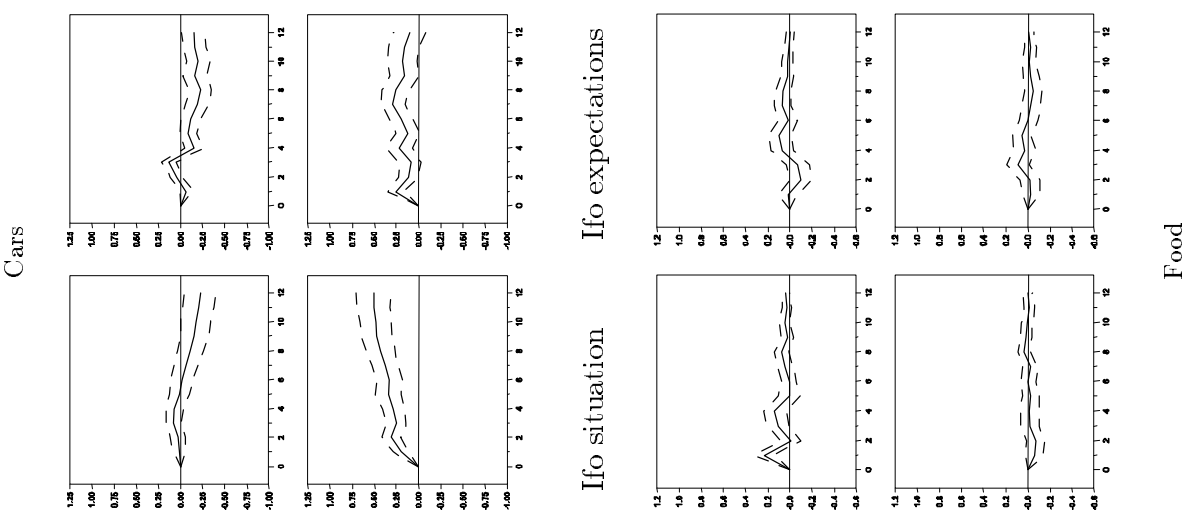

0
0
0
0
0
0
0
0
0
0
0
0
0
00
0
0
0
0
01
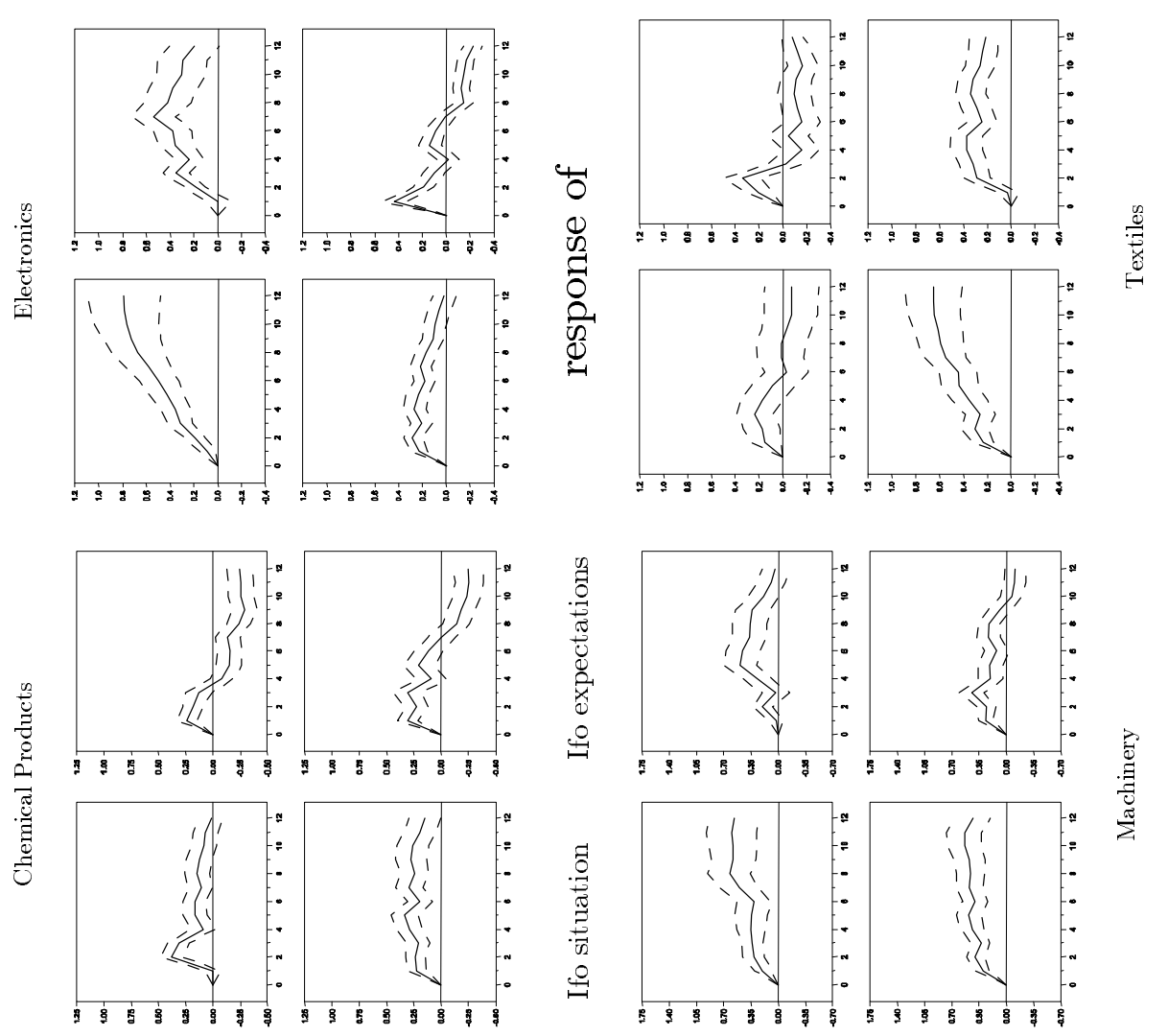

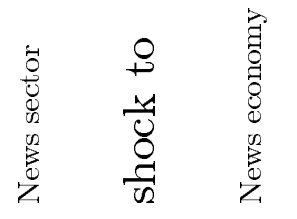

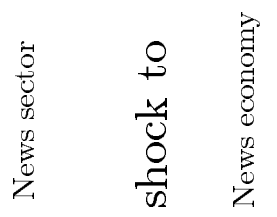




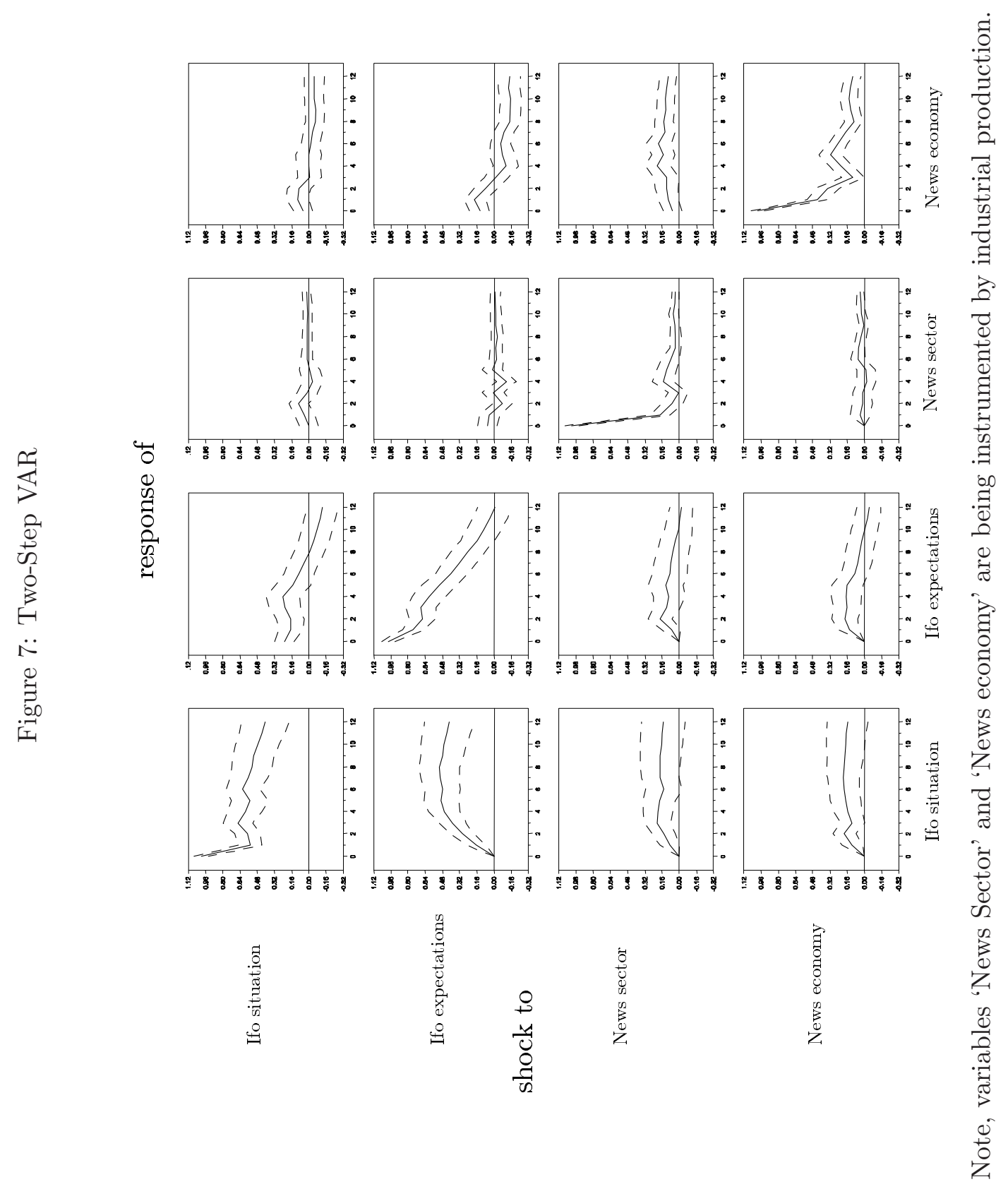




\section{References}

Beaudry, P. and Portier, F. (2004). When can changes in expectations cause business cycle fluctuation in neo-classical settings? NBER Working Paper 10776.

Benhabib, J. and Farmer, R. E. A. (1996). Indeterminacy and sector-specific externalities. Journal of Monetary Economics, 37(3):421-443.

Christiano, L. J. and Fitzgerald, T. J. (1998). The business cycle: It's still a puzzle. Federal Reserve Bank of Chicago Economic Perspectives, 22:56-83.

Cooley, T. and LeRoy, S. (1985). Atheoretical macroeconometrics: a critique. Journal of Monetary Economics, 16:283-308.

Cooper, R. and Andrew, J. (1988). Coordinating coordination failures in Keynesian models. Quarterly Journal of Economics, 103:441-463.

Cooper, R. and Haltiwanger, J. (1996). Evidence on macroeconomic complementarities. Review of Economics and Statistics, 78(1):78-93.

Denton, F. (1978). Single equation estimators and aggregation restrictions when equations have the same set of regressors. Journal of Econometrics, 8:173-179.

Duggal, V., Saltzman, C., and Klein, L. (1995). Infrastructure and productivity: A nonlinear approach. paper presented at the 7th World Congress of the Econometric Society in Tokyo, Japan, 22-29 August.

Fritsche, U. and Stephan, S. (2002). Leading indicators of German business cycles: An assessment of properties. Journal of Economics and Statistics, 222(3):289-315.

Giannini, C. (1992). Topics in structural VAR econometrics. Springer Verlag, Berlin.

Granger, C. (1980). Testing for causality. A personal viewpoint. Journal of Economic Dynamics and Control, 2:329-352.

Hornstein, A. (2000). The business cycle and industry comovement. Federal Reserve Bank of Richmond Economic Quarterly, 86/1. 
Hüfner, F. and Schröder, M. (2002). Forecasting economic activity in Germany-how useful are sentiment indicators? Discussion Paper 02-56, ZEW.

Jaimovich, N. and Rebelo, S. T. (2006). Can news about the future drive the business cycle? NBER Working Paper 12537.

Kawai, M. (1980). Exchange rate-price causality in the recent floating period. In Bigman, C. and Taya, C., editors, The functioning of floating exchange rates. Theory, evidence, and policy implications, pages 189-211. Ballinger, Cambridge.

Lucas, R. E. (1977). Understanding business cycles. In Brunner, K. and Meltzer, A. H., editors, Stabilization of the Domestic and International Economy, volume 5 of CarnegieRochester Conference Series on Public Policy. North-Holland, Amsterdam.

Mora, J. V. R. and Schulstad, P. (2007). The effect of GNP announcements on fluctuations of GNP growth. European Economic Review, 51(8):1922-1940.

Murphy, K. K., Shleifer, A., and Vishny, R. W. (1989). Building blocks of market clearing business cycle models. In Blanchard, O. J. and Fisher, S., editors, Macroeconomics Annual 1989. MIT Press, Cambridge, Mass.

Nerb, G. (2004). Survey activity of the Ifo institute. In Sturm, J.-E. and Wollmershäuser, T., editors, Ifo Survey Data in Business Cycle and Monetary Policy Analysis. Physica Verlag.

Nierhaus, W. and Sturm, J.-E. (2007). Methods of economic forecasting and business cycle indicators. In Goldrian, G., editor, Handbook of Survey-Based Business Cycle Analysis, chapter 10, pages 117-142. Edward Elgar Publishing, Cheltenham.

Oppenländer, K., editor (1997). Business cycle indicators. Avebury, Aldershot etc.

Pigou, A. (1927). Industrial Fluctuations. MacMillan, London.

Rebelo, S. T. (2005). Real business cycle models: Past, present, and future. Scandinavian Journal of Economics, 107(2):217-238. 
Schmitt-Grohe, S. (1997). Comparing four models of aggregate fluctuations due to selffulfilling expectations. Journal of Economic Theory, 72(1):96-147.

Sims, C. (1980). Macroeconomics and reality. Econometrica, 48(1):1-48.

Strigel, W. (1990). Business cycle surveys: A new quality in economic statistics. In Klein, P., editor, Analyzing modern business cycles. Essays honoring G.H. Moore, chapter 5, pages 69-84. M.E. Sharpe, Inc., Arnouk (NY) and London.

Sturm, J.-E. and Wollmershäuser, T., editors (2004). Ifo Survey Data in Business Cycle and Monetary Policy Analysis. Physica Verlag.

Theil, H. (1955). Recent experiences with the Munich business test: An expository article. Econometrica, 23:184-192.

Veldkamp, L. and Wolfers, J. (2007). Aggregate shocks or aggregate infromation? Costly information and business cycle comovement. Journal of Monetary Economics. forthcoming.

Zarnowitz, V. (1992). Business cycles: Theory, history, indicators and forecasting, volume 27 of NBER Studies in Business Cycles. The University of Chicago Press, Chicago and London. 